\title{
Absent/Hypoplastic Fetal Nasal Bone and Its Association with Aneuploidies
}

\author{
Pratima Dash $^{1} \cdot$ Ratna Dua Puri $^{1} \cdot$ Manisha Goyal $^{2} \cdot$ Sunita Bijarnia $^{1} \cdot$ \\ Meena Lall ${ }^{1} \cdot$ Udhaya Kotecha $^{1} \cdot$ Ishwar Chander Verma $^{1}$
}

Received: 25 May 2015/Accepted: 27 August 2015/Published online: 23 September 2015

(C) Society of Fetal Medicine 2015

\begin{abstract}
Absence or hypoplasia of fetal nasal bone (AHNB) in the first or second trimester scans, with increased risk for trisomy 21 has been shown in many studies. In view of reports of ethnic difference in the size of the nasal bone the usefulness of its evaluation in Indian women is desirable. All pregnant women presenting to the Genetic Clinic from Jan 2012 through April 2014 with ultrasound finding of absent or hypoplastic nasal bone, in either first or second trimester of pregnancy were prospectively enrolled in the study, after obtaining informed consent. Nasal bone hypoplasia was defined as nasal bone length less than 2.5 th percentile for the period of gestation. The presence of other associated soft markers for aneuploidies along with result of biochemical screening was also recorded. All the patients were counseled for the appropriate invasive testing. Chorionic villi or amniotic fluid cells were analyzed using FISH studies for chromosome no. 13, 18, 21 and sex chromosomes and also cultured for the complete karyotype. The gestational age varied from 11 to 22 weeks, with the majority being between 17 and 20 weeks. The cohort of 92 patients was divided into five groups: Group 1: Isolated hypoplastic nasal bone with low risk in biochemical screening and no additional soft marker-30 cases (32. $6 \%$ ); Group 2: Isolated absent nasal bone-25 cases $(27.1 \%)$; Group 3: AHNB with additional ultrasound markers-29 cases (31.5\%); Group 4: Absent nasal bone (ANB) with high
\end{abstract}

Pratima Dash

dr_dprat@yahoo.com

1 Center of Medical Genetics, Sir Ganga Ram Hospital, Rajinder Nagar, New Delhi 110060, India

2 Pediatrics Genetic and Research Lab, Department of Pediatrics, Maulana Azad Medical College, New Delhi, India risk in biochemical screening with no other ultrasound abnormality -7 cases (7.6\%); and Group 5: ANB with additional ultrasound findings and abnormal biochemical screen ( 1 case). The karyotype in $20(21.7 \%)$ of 92 cases was abnormal. In group 1 three cases $(10 \%)$ had chromosomal abnormalities-47, XXX; mosaic 45, X; 47, XXY. In group 2, three (12\%) cases had trisomy 21 . In group 3, $12(41.3 \%)$ cases had chromosomal abnormality-trisomy 21 (10), derivative 22 (1), triploidy (1). In group 4 trisomy 21 was present in two $(28.5 \%)$ cases. The one patient in group 5 had a normal fetal karyotype. The present study shows that isolated absent/hypoplastic nasal bone was associated with chromosomal disease in 10-12\% of cases. However, cases where AHNB was associated with ultrasound anomalies, or with high risk biochemical studies yielded abnormal chromosomes in a significantly larger number of patients (41.4 and $28.5 \%$ respectively). It is, therefore, recommended that this group should always be analyzed for chromosomal abnormalities. Recent studies suggest that nasal bone length may be smaller in fetuses in Indian women. If standards derived in Indian women are used, the yield of chromosomal abnormalities may be greater.

Keywords Absent nasal bone - Hypoplastic nasal bone . Aneuploidy $\cdot$ Invasive test $\cdot$ Amniocentesis

\section{Introduction}

Nasal root depth is abnormally short in Down syndrome patients by anthropometric studies in approximately $50 \%$ of cases [1]. Nasal bones are easily identifiable markers on genetic sonograms. The association of absence or hypoplasia of fetal nasal bone (AHNB) in the first or second 
trimester scans, with increased risk for trisomy 21 has been shown in many studies [2-10]. However, with advancing gestation the nasal bone is more frequently visible in trisomy 21 fetuses, although it is frequently hypoplastic as compared to normal fetuses [4, 7, 8, 11]. Inclusion of fetal nasal bone in first trimester screening, which includes maternal age, assessment of serum free $\beta$-human chorionic gonadotropin ( $\beta$-hCG) and pregnancy associated plasma protein- A (PAPP-A) and ultrasound markers like nuchal translucency (NT) and fetal heart rate (FHR), increases the performance of the screening test for detecting aneuploidies [12].

Nasal bone hypoplasia has been defined arbitrarily in many ways. These includes nasal bone length less than 10 th centile [4], less than 2.5 th centile [7, 13], less than $2.5 \mathrm{~mm}[8,11]$, and biparietal diameter to nasal bone ratio $>10$ or $11[14,11]$. There have been reports of differences in fetal nasal bone length in fetus of different ethnicities. There are studies which indicate that fetal nasal bone length is shorter in Indian population when compared with other ethnicities [15]' We studied 92 Indian women with the ultrasound feature of absent or hypoplastic nasal bone, in whom chromosomal studies had been done, to determine its association with chromosomal abnormalities. The effect of ethnic difference on the outcome was also examined.

\section{Materials and Methods}

All pregnant women presenting to the Genetic Clinic from Jan 2012 through April 2014 with ultrasound finding of absent or hypoplastic nasal bone in either first or second trimester of pregnancy were prospectively enrolled in the study, after obtaining informed consent. The criteria to consider nasal bone hypoplasia was nasal bone length less than 2.5th percentile for the period of gestation as described by Cicero et al. [8]. Concurrently, the values of hypoplastic nasal bone length were matched with the available Indian standards [15]. The ultrasound images of the nasal bone were analyzed to confirm that nasal bone had been measured correctly, as the cases were analyzed by different sonologists. The presence of other associated soft markers for aneuploidies, along with results of biochemical screening was also recorded. The biochemical screening included the first trimester, triple or quadruple tests. All the patients with either an isolated hypoplastic nasal bone or with presence of additional ultrasound features or biochemical markers were counseled for the appropriate invasive testing which included chorionic villus sampling or amniocentesis. Chorionic villi or amniotic fluid cells were analyzed using FISH studies for chromosome no. 13, 18, 21 and sex chromosomes and also cultured for the complete karyotype.

\section{Results}

Ninety-two cases were enrolled. The gestational age varied from 11 to 22 weeks, with the majority of cases between 17 and 20 weeks. All the cases enrolled were of Asian Indian origin. Seven $(7.6 \%)$ of the cases had absent nasal bone diagnosed in the first trimester and the rest (85) were diagnosed in the second trimester (13-22 weeks). Of the 85 patients in second trimester 45 had absent nasal bone and 40 had hypoplastic nasal bone.

For analysis the cohort of 92 patients was divided into five groups as shown in Table 1. The karyotype in 20 $(21.7 \%)$ of 92 cases was abnormal. The karyotypic abnormality in each group (Table 1). Seven cases in first trimester, two cases were diagnosed with trisomy 21. One of the two abnormal cases had increased NT and the other

Table 1 Groups of patients with absent/hypoplastic nasal bone and the associated chromosomal abnormalities

\begin{tabular}{|c|c|c|c|c|c|c|}
\hline Group & $\begin{array}{l}\text { Nasal bone absent/ } \\
\text { hypoplastic }\end{array}$ & $\begin{array}{l}\text { Additional ultrasound } \\
\text { findings }\end{array}$ & $\begin{array}{l}\text { Biochemical } \\
\text { screening }\end{array}$ & No. of cases & $\begin{array}{l}\text { No. of abnormal } \\
\text { cases }\end{array}$ & $\begin{array}{l}\text { Type of karyotype } \\
\text { abnormalities }\end{array}$ \\
\hline I & $\begin{array}{l}\text { Isolated hypoplastic } \\
\text { nasal bone }\end{array}$ & Nil & Low risk ${ }^{\mathrm{b}}$ & $30(32.6 \%)$ & $3(10 \%)$ & $\begin{array}{l}\text { 47,XXX (1); mosaic 45,X(1); } \\
\text { 47,XXY (1) }\end{array}$ \\
\hline II & $\begin{array}{l}\text { Isolated absent nasal } \\
\text { bone }\end{array}$ & Nil & Low risk & $25(27.1 \%)$ & $3(12 \%)$ & Trisomy 21 (3) \\
\hline III & $\begin{array}{l}\text { Absent/hypoplastic } \\
\text { nasal bone }\end{array}$ & Present $^{\mathrm{a}}$ & Low risk & $29(31.5 \%)$ & $12(41.3 \%)$ & $\begin{array}{l}\text { Trisomy } 21(10) \text {; derivative } \\
22(1) \text {; triploidy (1) }\end{array}$ \\
\hline IV & Absent nasal bone & Nil & High risk ${ }^{c}$ & $7(7.6 \%)$ & $2(28.5)$ & Trisomy 21 (2) \\
\hline V & Absent nasal bone & Present & High risk & 1 & 0 & Nil \\
\hline
\end{tabular}

${ }^{a}$ The additional ultrasound markers were echogenic intracardiac focus, choroid plexus cyst, ventriculomegaly, renal pelviectasis, single umbilical artery, congenital talipesequinovarus, bilateral sandal gap, increased nuchal fold thickness and echogenic kidneys

${ }^{\mathrm{b}}$ Low risk - the adjusted risk in either first trimester, triple or quadruple test for trisomy 21 is $<1: 250$ and for trisomy 13/18 is $<1: 100$

${ }^{c}$ High risk - the adjusted risk in either first trimester, triple and quadruple test for trisomy 21 is $>1: 250$ and for trisomy 13/18 is $>1: 100$ 
Table 2 Comparison of the nasal bone length (5th centiles) - Indian and western standard

\begin{tabular}{llll}
\hline $\begin{array}{l}\text { Gestation } \\
(\text { wks })\end{array}$ & $\begin{array}{l}\text { Indian standard } \\
(\mathrm{mm}) \text { 5th centile }\end{array}$ & $\begin{array}{l}\text { Western standard } \\
(\mathrm{mm}) \text { 5th centile }\end{array}$ & $\begin{array}{l}\text { Current } \\
\text { study }(5 \\
\text { cases })\end{array}$ \\
\hline 16 & 2.49 & 3.4 & 3.0 \\
17 & 2.7 & 4.0 & 3.2 \\
18 & 3.4 & 4.3 & \\
19 & 3.8 & 5.0 & 4.0 \\
20 & 4.05 & 5.2 & 4.2 \\
21 & 4.2 & 5.6 & 4.5 \\
22 & 4.4 & 5.8 & \\
\hline
\end{tabular}

case had increased NT with tricuspid regurgitation and absent flow in ductus venosus.

Evaluation of values of nasal bone length by comparing with both the Western and Indian data revealed that in 5 cases, the nasal bone length was small by Western standards, however by Indian charts the value was normal for the gestational age (more than 5 centile). The amniotic fluid culture analysis showed normal karyotype in all the 5 cases (Table 2).

\section{Discussion}

Screening for Down syndrome and other aneuploidies by using ultrasound markers is an important part in prenatal fetal evaluation. The present cohort of 92 patients, included pregnancies with absent and hypoplastic nasal bone in both first and second trimester.

The cohort was divided into five groups so as to better define the association between absent/hypoplastic nasal bone in presence or absence of associated anomalies and low/high risk results in biochemical screening.

Category A included cases with isolated hypoplastic nasal bone with no associated ultrasound anomalies and low risk in biochemical screening. This group encompassed 30 cases. Three cases revealed sex chromosomal abnormalities (10 \%): 47, XXX; mosaic 45, X; 47, XXY. Association of AHNB nasal bone with sex chromosome abnormalities has been described previously in many studies [8].

Category B comprised cases with absent nasal bone with no associated ultrasound abnormalities and low risk in biochemical screen. This cohort of 25 patients revealed chromosomal abnormality (trisomy 21 ) in 3 cases (12\%). This finding is consistent with many previous studies [210].

The third category C included 29 cases with AHNB with additional ultrasound abnormalities but with negative biochemical screening results. Twelve cases $(41.3 \%)$ showed compound chromosomal aberrations like trisomy 21 (10), derivative 22 (1) and triploidy (1).

Category 4 involved cases with AHNB with high risk in biochemical screen however there were no added ultrasound abnormalities. This group included 7 cases out of which 2 cases were diagnosed with trisomy $21(28.5 \%)$.

The last category 5 involved one case with absent nasal bone with additional ultrasound findings (choroid plexus cyst) and high risk in biochemical screen which unexpectedly demonstrated normal karyotype. The pregnancy was continued further and obstetric ultrasound later in the gestation did not show any abnormality. Post delivery follow up has not been done.

The finding of sex chromosome abnormalities in our group of patients with isolated hyoplastic nasal bone drives one to contemplate whether non invasive prenatal testing (NIPT) can be offered to these couple as the next level screening test. The detection rate of NIPT for sex chromosome abnormalities is $90-93 \%$ only [16].

The study shows that almost $85-90 \%$ cases of isolated AHNB are observed with normal chromosome which provides great deal of reassurance to the couple.

Recent studies have established that nasal bone length is smaller in Indian women [15]. The current cohort of patients included 5 cases where nasal bone length was less than 5th centile for the gestation according to Western standards but the values were normal for the gestation by Indian standards. Usage of Indian criteria for nasal bone length evaluation could have averted the invasive procedures in these cases. This further reinstates that Indian standards must be used before subjecting the pregnant women to an invasive procedure, which are associated with risk of miscarriage. This would enhance the yield of the invasive tests.

\section{Conclusion}

The present study shows that isolated absent/hypoplastic nasal bone was associated with chromosomal disease in $10-12 \%$ of cases. However, cases where AHNB was associated with ultrasound anomalies, or with high risk biochemical studies yielded abnormal chromosomes in a significantly larger number of patients (41.4 and $28.5 \%$ respectively). It is, therefore, recommended that this group should always be analyzed for chromosomal abnormalities. Furthermore, if Indian standards derived for nasal bone length are used, the yield of chromosomal abnormalities would be greater.

\section{Compliance with Ethical Standards}

Conflict of Interest None. 


\section{References}

1. Farkas LG, Katic MJ, Forrest CR, et al. Surface anatomy of the face in Down's syndrome: linear and angular measurements in the craniofacial regions. J Craniofac Surg. 2001;12:373-9.

2. Cicero S, Curcio P, Papageorghiou A, et al. Absence of nasal bone in fetuses with trisomy 21 at 11-14 weeks of gestation: an observational study. Lancet. 2001;358:1665-7.

3. Otano L, Aiello H, Igarzabal L, et al. Association between first trimester absence of fetal nasal bone on ultrasound and Down syndrome. Prenat Diagn. 2002;22:930-2.

4. Cusick W, Provenzano J, Sullivan CA, Gallousis FM, Rodis JF. Fetal nasal bone length in euploid and aneuploidfetuses between 11 and 20 weeks' gestation: a prospective study. J Ultrasound Med. 2004;23:1327-33.

5. Cicero S, Bindra R, Rembouskos G, et al. Fetal nasal bone length in chromosomally normal and abnormal fetuses at 11-14 weeks of gestation. J Matern Fetal Neonatal Med. 2002;11:400-2.

6. Orlandi F, Bilardo CM, Campogrande M, et al. Measurement of nasal bone length at 11-14 weeks of pregnancy and its potential role in Down syndrome risk assessment. Ultrasound Obstet Gynecol. 2003;22:36-9.

7. Odibo AO, Sehdev HM, Dunn L, et al. The association between fetal nasal bone hypoplasia and aneuploidy. Obstet Gynecol. 2004;104:1229-33.

8. Cicero S, Sonek JD, McKenna DS, et al. Nasal bone hypoplasia in trisomy 21 at 15-22 weeks' gestation. Ultrasound Obstet Gynecol. 2003;21:15-8.
9. Cicero S, Bindra R, Rembouskos G, et al. Integrated ultrasound and biochemical screening for trisomy 21 using nuchal translucency, absent fetal nasal bone, free B-hCG and PAPP-A at 11 to 14 weeks. Prenat Diagn. 2003;23:306-10.

10. Vintzileos A, Walters C, Yeo L. Absent nasal bone in the prenatal detection of fetuses with trisomy 21 in a high-risk population. Obstet Gynecol. 2003;101:905-8.

11. Viora E, Errante G, Sciarrone G, et al. Fetal nasal bone and trisomy 21 in the second trimester. Prenat Diagn. 2005;25:511-5.

12. Kagan KO, Cicero S, Staboulidou I, et al. Fetal nasal bone in screening for trisomies 21,18 and 13 and Turner syndrome at 11-13 weeks of gestation. Ultrasound Obstet Gynecol. 2009;33:259-64.

13. Sonek J, Nicolaides KH. Prenatal ultrasonographic diagnosis of nasal bone abnormalities in three fetuses with Down syndrome. Am J Obstet Gynecol. 2002;186:139-41.

14. Bromley B, Lieberman E, Shipp TD, Benacerraf BR. Fetal nose bone length: a marker for Down syndrome in the second trimester. J Ultrasound Med. 2002;21:1387-94.

15. Sharma A, Tayal T, Narayani BH, et al. Nasal bone length: the long and short of it. Evaluation of the reference values for the fetal nasal bone length at 16 to 25 weeks of gestational age in an Indian population. Prenat Diagn. 2013;33:800-3.

16. Gil MM, Quezada MS, Revello R, Akolekar R, Nicolaides KH. Analysis of cell-free DNA in maternal blood in screening for fetal aneuploidies: updated meta-analysis. Ultrasound Obstet Gynecol. 2015;45:249-66. 